Original Research Report

\title{
Terpenoid Isolation from Baccaurea Lanceolata Muell. Arg Fruit
}

\author{
Kunti Nastiti ${ }^{1}$, Samsul Hadi ${ }^{2}$ \\ ${ }^{1}$ Departement of Public Health, Universitas Sari Mulia. Banjarmasin, Indonesia. \\ ${ }^{2}$ Department of Pharmacy, Universitas Lambung Mangkurat. Banjarmasin, Indonesia.
}

Article History
Received:
27.02 .2020
Revised:
29.02 .2020
Accepted:
03.03 .2020
*Corresponding Author:
Kunti Nastiti
Email:
kuntinastiti86@gmail.com

This is an open access article, licensed under: $\mathrm{CC}-\mathrm{BY}-\mathrm{SA}$
Abstract: Fruits of Baccaurealanceolata is commonly used by tribe banjar in south Borneo to protect the skin damages due to sun light. People apply the pulverized fruits to the skin that will be exposed to sunlight. Antioxidant bioassay method (DPPH) is used to prove the effectiveness of the fruits. Baccaurea lanceolata fruitsvwere extracted by $70 \%$ ethanol, followed by fractionation with n-hexane, ether, ethyl acetate and methanol to give n-hexane $(\mathrm{fr}-\mathrm{H})$, ether $\left(\mathrm{fr}^{-} \mathrm{Et}_{2} \mathrm{O}\right)$, ethyl acetate (fr. EtOAc) and methanol (fr. $\mathrm{MeOH}$ ) fractions respectively. Preparative TLC $\left(\mathrm{SiO}_{2}\right)$ of the fr. EtOAc that showed the the highest antioxidant activity among those fractions. Based on spectroscopic data and comparison with reported data, the isolated compounds were identified as $\beta$-Sitosterol. Baccaurea lanceolata fruit has active compounds as antioxidants. Ethyl acetate fraction has the greatest antioxidant activity compared to other fractions. One of the compounds isolated and identified from the ethyl acetate fraction is the $\beta$-sitosterol compound.

Keywords: Antioxidan, Baccaurea Lanceolata, $\beta$-Sitosterol. 


\section{Introduction}

The local wisdom of the Banjar tribe in South Kalimantan is truly extraordinary in terms of health and beauty. Not only have the Indonesian people who take advantage of this potential, but foreign communities also used it [1] [2].

The Banjar tribe that lives around the forests in South Kalimantan until now still maintain the tradition by utilizing the surrounding plants for treatment or health care. One of the uses of natural materials by the Banjar tribe is Limpasu fruit (Baccaurea lanceola) which comes from the Limpasu tree and is commonly used for skin care. This fruit is used when they will go to the fields by applying it to the skin with the aim of protecting the skin from the sun. UV rays from the sun have a fairly strong energy and can ionize the atoms in the layer of the atmosphere, so that it is classified as radiation that is harmful to human skin if emitted in a large intensity. UV light can cause the formation of free radicals and trigger oxidative stress if the formation of ROS (Reactive Oxygen Species) exceeds the ability of endogenous antioxidant defense systems [3] [4] [5]. Detection of antioxidant properties in limpasu (Baccaurea lanceola) is the basis of this study.

\section{Methodology}

2.1. Tools

There are some tools used, namely:

- L Acura ${ }^{\circledR} 825$ (Socorex, Switzerland),

- Duran ${ }^{\circledR}$ enclosed test tubes (Schott North America Inc., USA),

- separating funnel $500 \mathrm{~mL}$,

- round bottom flask (Schott North America Inc., USA),

- heating mantle,

- ultrasonic device,

- centrifugation device,

- homogenizer \& glassware,

- UV-Vis spectrophotometer (Perkin Elmer Inc., USA),

- quartz silica cuvette (Sigma Chem. Co., USA),

- efendorf,

- analitical balance and semi micro balance BP 160P (Sartorius, USA),

- electric Scaltec SBC 22 (Microprecision Caliberacion Inc. , USA),

- waterbath,

- micropipette 0.5

\subsection{Material}

Baccaurea lanceolata, methanol p.a; chloroform p.a; ethyl acetate p.a; n-hexane p.a; methanol. Ethyl acetate, ether, n-hexane. Silica gel 60 PF254 containing gypsum, Aluminum TLC (Thin Layer Chromatography), chromatographic plates, DPPH, ascorbic acid.

\section{Extraction and Isolation}

Baccaurea lanceolata extracted with $70 \%$ alcohol, fractionated with n-hexane, ether, ethyl acetate and methanol to produce fraction of n-hexane ( $\mathrm{fr}-\mathrm{H})$; ether fraction (fr-E); ethyl acetate fraction (fr-EA) and methanol fraction (fr-M). Based on the activity test (DPPH), fr-EA is the most active fraction as an antioxidant so it is fractionated with VLC (Vacuum liquid Chromatography) and 18 fractions are obtained. Based on the similarity of the TLC image, fractions with similar TLC profiles are combined. The obtained fractions were then isolated by preparative thin layer chromatography method.

\section{Spectra Analisys}

The isolates obtained from the ethyl acetate fraction by preparative thin layer chromatography method were then analyzed by their chemical structure using the GC-MS (Gass chromatography-Mass Spectra) method to determine the level of purity and molecular weight by matching the data based from the instrument.

The isolates were examined for the total carbon amount by the C-NMR method. The composition of $\mathrm{CH} 2, \mathrm{CH} 3, \mathrm{CH}$, and $\mathrm{C}$ C-NMR data was compared with DEPT. To see the environment of hydrogen isolates were examined by H-NMR. 
Kunti Nastiti, Samsul Hadi.

Terpenoid Isolation from Baccaurea Lanceolata Muell. Arg Fruit.

International Journal of Clinical Inventions and Medical Sciences, vol. 2, no. 1, pp. 27-32, March 2020. DOI: 10.36079/lamintang.ijcims-0201.79

\section{Results and Discussion}

Baccaurea lanceolata (Euphorbiaceae) fruit, the compound was successfully isolated with a bioassay guided (DPPH) approach. This isolate was isolated by preparative thin layer chromatography method with n-hexane: ethyl acetate 4: 1 mobile phase with retention factor 0.5 .

\subsection{Isolate Structure Analysis}

MS (m/z): 414(M); 396; 381; 329; 255; 231; 213; 159; 145; 81; 57.

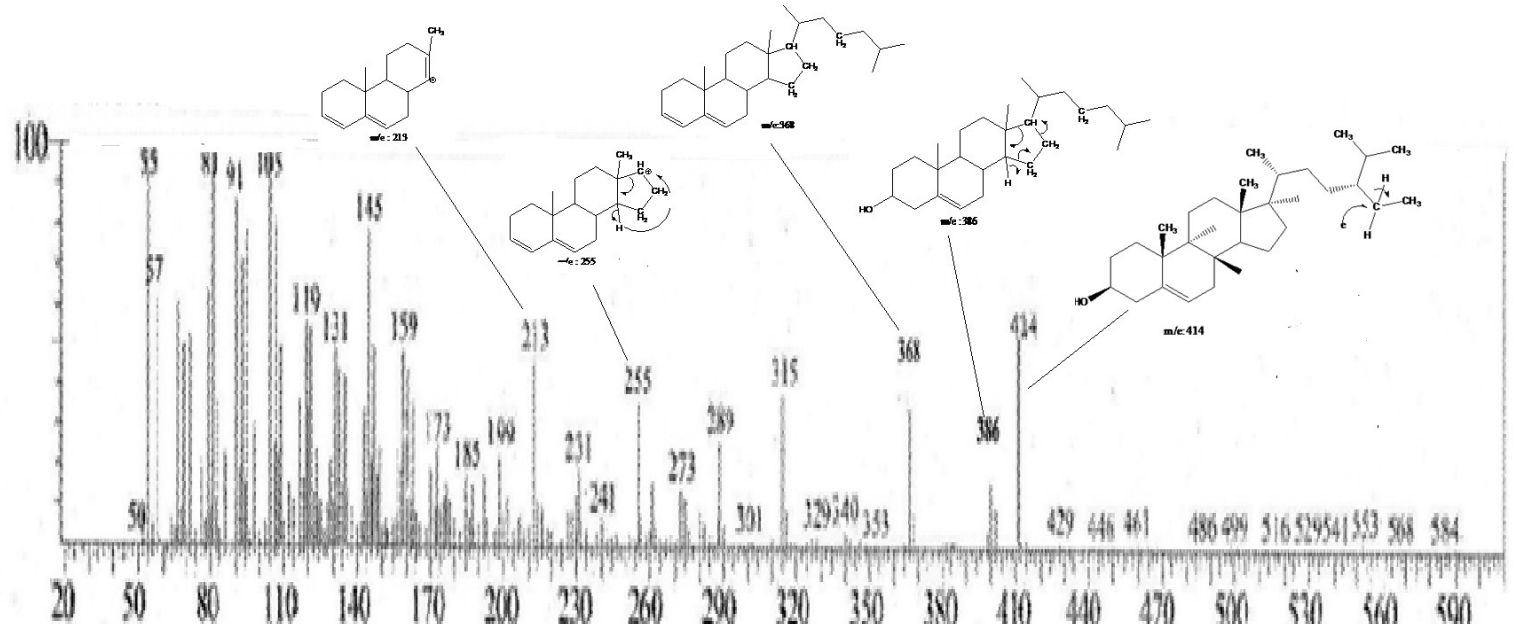

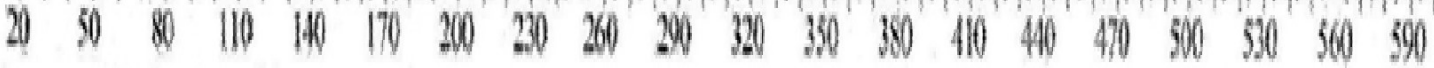

Figure 1. GC MS Analysis

\subsection{C-NMR and H-NMR Analysis}

This isolate is a white needle-shaped crystal. Based on GC-MS data, this compound has $\mathrm{m} / \mathrm{z} 414$ supported by $414(\mathrm{M})$ fragmentation; 396; 381; 329; 255; 231;213; 159; 145; 81; 57.

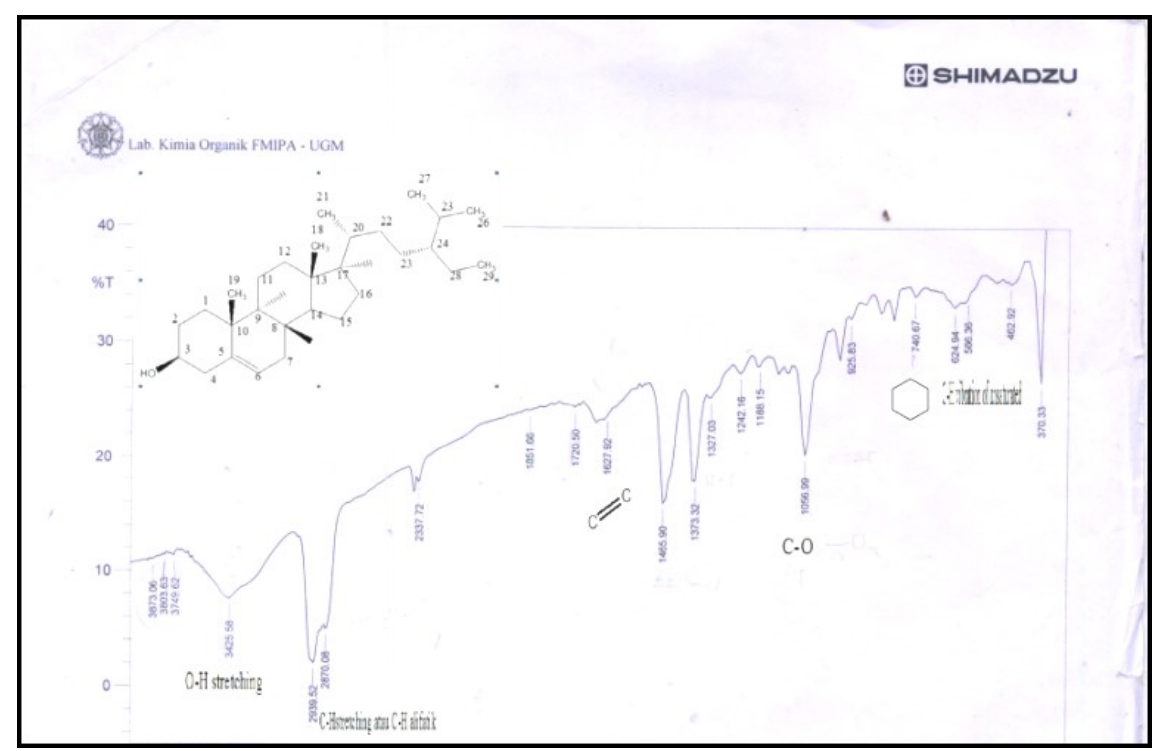

Figure 2. C-NMR 
Data 13C-NMR shows 121.73 and 140.77, this shows the Carbon Double Bond bond, and the signal 140.77 does not appear in DEPT, this shows the carbon C atom is a Quarterner (C5) and what appears is the 121.73 signal at position to the top this shows the $\mathrm{CH}(\mathrm{C} 6)$ bond. 71.82 signal appears this shows that carbon is bound with high electronegativity combined with DEPT data facing upward this shows the $\mathrm{CH}(\mathrm{C} 5)$ bond. This spectra also shows 29 sigcarbon in which there are six methyl $(\mathrm{CH} 3)$, nine methylene $(\mathrm{CH})$, sebelasa methane $(\mathrm{CH} 2)$ and three quaternary carbon $(\mathrm{C})$.

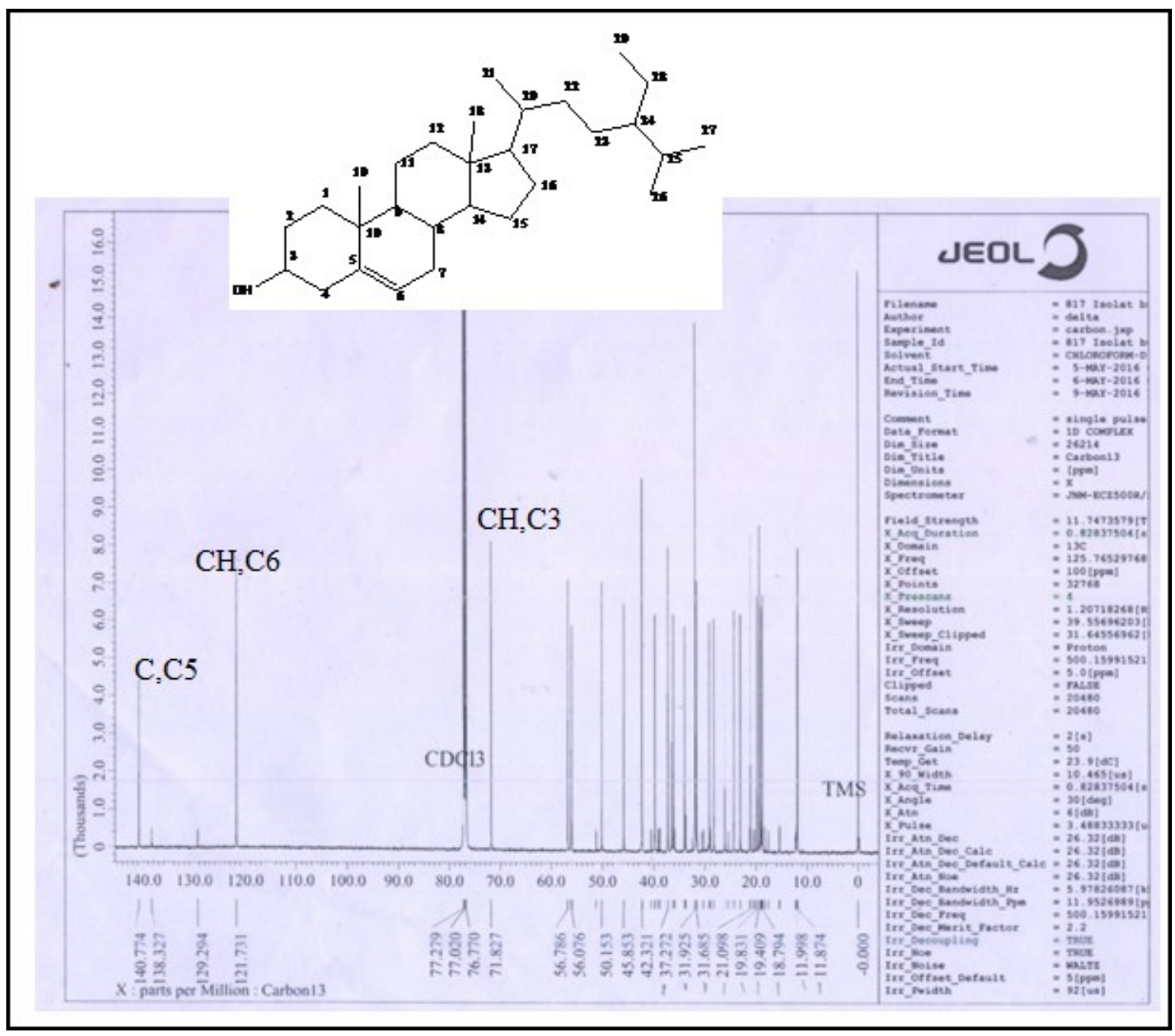

Figure 3. H-NMR

1H-NMR data Appears a signal $\delta 3.52$ multiplets indicate the core of steroids in $\mathrm{H}$ which is bound to the atom (C3). Signal multiplet $\delta 5.35$ is hydrogen olefini bound to (C6) a skeleton of steroids. Signals 0.68 and 1.83 are isolated and singlets appear with integrals 3 in positions (C18) and (C19). The appearance of the singlet at 0.829 with integral 9 shows the similarity of chemical shifts and accumulates into 9 hydrogen namely (C26); (C27); (C29).

Based on GCMS data, NMR spectra data and literature data were identified as $\beta$-Sitosterol [6, 7]. 
The antioxidant ability of triterpenes from other species varies from size $\mu \mathrm{g} / \mathrm{ml}$ or $\mu \mathrm{M}$ to $\mathrm{mg} / \mathrm{ml}$ or $\mathrm{mM}$. Three new triterpenes compounds found from the roots of Momordica charantia have antioxidant activity with IC50 values $268.5 \pm 7.9,352.1 \pm 11.5458 .9 \pm 13.0 \mu \mathrm{M}$ [8]. Chilianthin B, chilianthin $\mathrm{C}$, and chilianthin A from Betula platyphylla var. japonica bark shows antioxidant ability with IC50 between $4.48-43.02 \mu \mathrm{M}$ by DPPH method [9].

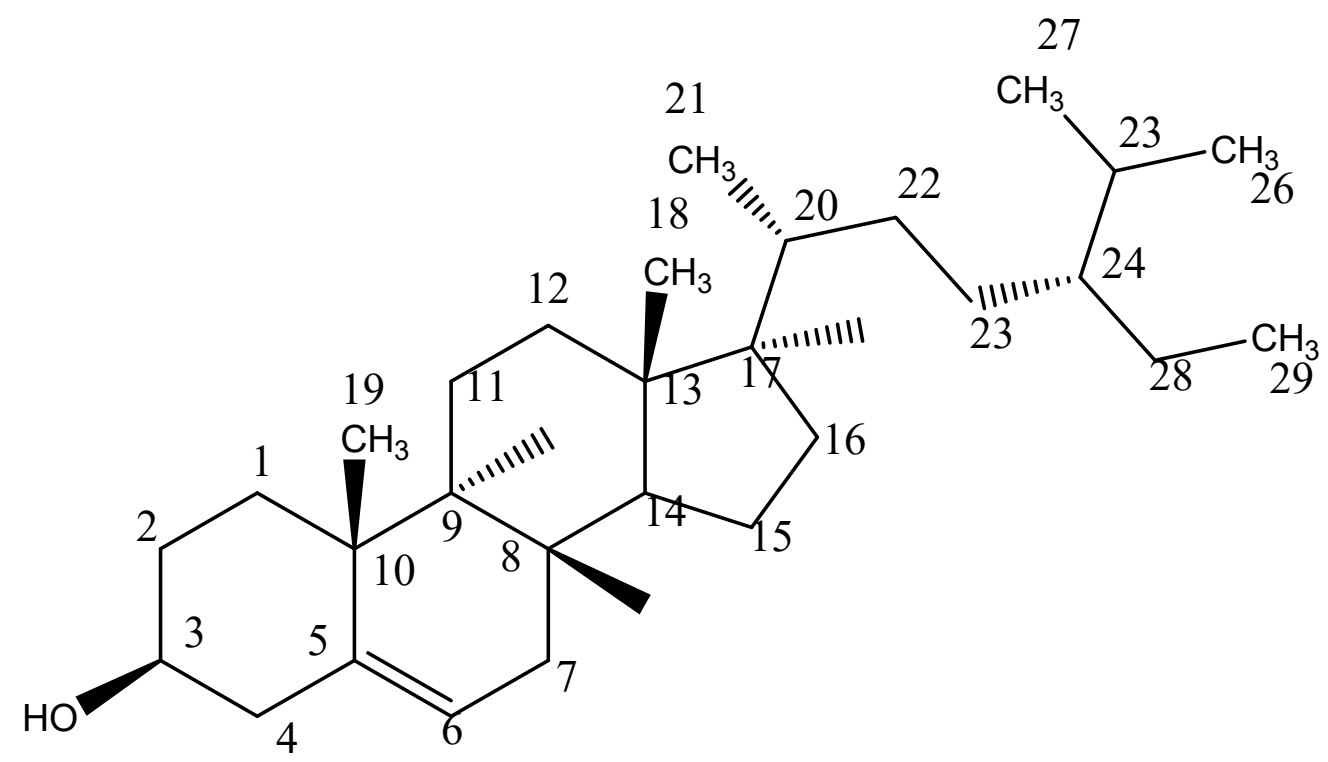

Figure 4. Structure of $\beta$-sitosterol $\left(\mathrm{C}_{29} \mathrm{H}_{50} \mathrm{O}\right)$

Triterpen glycoside 3-O- (beta-D-glucopyranosyl) -hederagenin isolate from Hedera colchica has the ability of antioxidant activity $30 \mu \mathrm{g} / \mathrm{ml}$ [10]. Oleanolic acid isolated from Viscum articulatum, Burm. (Loranthaceae) has antioxidant abilities and inhibits the release of nitric oxid seen in plasma nitrate / nitrite (Bachhav et al., 2011).

Anti-radical effect of Lantadene A from Lantana by DPPH method has antioxidant activity IC50: $0.027 \mathrm{mg} / \mathrm{ml}$; with hydroxyl radicals IC50: $0.937 \mathrm{mg} / \mathrm{ml}$; Superoxide anion radical IC50: $1,025 \mathrm{mg}$ $/ \mathrm{ml}$, with nitric oxide radicals IC50 $=0.075 \mathrm{mg} / \mathrm{mL}$ [4].

Antioxidant activity of Kopsia singapurensis Ridl triterpen more than $500 \mu \mathrm{g} / \mathrm{mL}$ containing lupeol, lupeol acetate, $\beta$-amyrin, $\beta$-amyrin acetate, $\beta$-amyrone, Stigmasterol [2].

F1 fraction of Ganoderma lucidum has higher antioxidant activity compared to other fractions with IC50 $0.90 \mathrm{mg} / \mathrm{ml}$, this is positively correlated with total total triterpenoids and total polyfenol [11]. $3 \alpha, 16 \alpha$-dihydroxyferna-7,9 -dien-12-one isolated from Lonicera quinquelocularis have antioxidant activity better than other isolates, namely $3 \alpha$-hydroxyferna-7, 9 (11), 22-trien-12-one; $3 \alpha-$

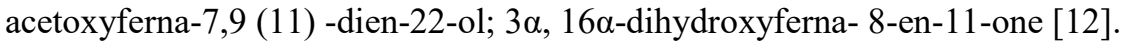

\section{Conclusion}

Baccaurea lanceolata fruit has active compounds as antioxidants. Ethyl acetate fraction has the greatest antioxidant activity compared to other fractions. One of the compounds isolated and identified from the ethyl acetate fraction is the $\beta$-sitosterol compound.

\section{References}

[1] M. F. A. Bakar, "Phytochemicalsand Antioxidative Properties of Borneo Indigenous Liposu (Baccaurealanolata) and Tampoi (Baccaureamacrocarpa) Fruits," Antioxidants, vol. 3, no. 3, pp. 516-525, 2014. 
Kunti Nastiti, Samsul Hadi.

Terpenoid Isolation from Baccaurea Lanceolata Muell. Arg Fruit.

International Journal of Clinical Inventions and Medical Sciences, vol. 2, no. 1, pp. 27-32, March 2020. DOI: 10.36079/lamintang.ijcims-0201.79

[2] L. Y. Shan, "Cytotoxic, antibacterial and antioxidant activity of triterpenoids from Kopsiasingapurensis," Ridl. J. Chem. Pharm. Res, vol. 6, no. 5, pp. 815-822, 2014.

[3] Y. S. Kwon and C. M. Kim, "Antioxidant Constituent from the Stem of Sorghum bicolor," Arch. Pharm. Res, vol. 26, no. 7, pp. 535-539, 2003.

[4] C. Gance, "In Vitro Antioxidant Activity Potential of Lantadene A, a Pentacyclic Triterpenoid of Lantana Plants," Molecules, vol.17, no.9, pp. 11185-11198, 2012.

[5] L. D. Manullang and E. T. Arung, "Toxicity Test and Antioxidant Fruit Extracts Kelepesoh (Baccaurealanceolata Miq. (Mull. Arg)," J. Science east Borneo, vol. 1, pp. 75-82, 2013.

[6] V. S. P. Chaturvedula and I. Prakash, "Isolation of Stigmasterol and $\beta$-Sitosterol from the dichloromethane extract of Rubussuavissimus," International Current Pharmaceutical Journal, vol. 1, no. 9, pp. 239-242, 2012.

[7] S. Yi and X. B. Chen, "Isolation and identification of an isomer of $\beta$-sitosterol by HPLC and GC-MS," Health, vol.1, pp. 203-206, 2009.

[8] C. H. Liu, "Antioxidant triterpenoids from the stems of Momordica charantia," Food Chemistry, vol. 118, no. 3, pp. 751-756, 2010.

[9] H. J. Eom, "Bioactivity-guided isolation of antioxidant triterpenoids from Betula platyphylla var. japonica bark," Bioorg Chem, pp. 66-97, 2016.

[10] I. Gülçin, "The antioxidant activity of a triterpenoid glycoside isolated from the berries of Hedera colchica: 3-O-(beta-D-glucopyranosyl)-hederagenin," Phytother Res, vol. 20, no. 2, pp. 130-134, 2006.

[11] M. Lin, "Bioactive Constituent Characterization and Antioxidant Activity of Ganoderma lucidum Extract Fractionated by Supercritical Carbon Dioxide," Sains Malaysiana, vol. 44, no.12, pp. 1685-1691, 2015.

[12] D. Khan, "Two New Antioxidant Triterpenoids from Lonicera quinquelocularis," Rec. Nat. Prod, vol. 8, no. 2, pp. 121-127, 2014. 